OPEN ACCESS

\title{
A Fundamental Approach to Electrochemical Analyses on Chemically Modified Thin Films for Barrier CMP Optimization
}

To cite this article: Rawana Yagan and G. Bahar Basim 2019 ECS J. Solid State Sci. Technol. 8 P3118

View the article online for updates and enhancements. 


\title{
A Fundamental Approach to Electrochemical Analyses on Chemically Modified Thin Films for Barrier CMP Optimization
}

\author{
Rawana Yagan ${ }^{1}$ and G. Bahar Basim $101,2, *, \mathrm{z}$ \\ ${ }^{1}$ Ozyegin University, Nisantepe Mevki, Cekmekoy, Istanbul 34794, Turkey \\ ${ }^{2}$ Department of Materials Science and Engineering, University of Florida, Gainesville, Florida 32611, USA
}

\begin{abstract}
Chemical Mechanical Planarization (CMP) process development for 10nm nodes and beyond demands a systematic understanding of atomic-scale chemical and mechanical surface interactions for the control of material removal, selectivity, and defectivity. Particularly the CMP of barrier/liner films is challenging with new materials introduced to better adhere the contact metal at the interface and limit the probability of metal diffusion to the transistors. The relative selectivity of the CMP removal rates of the barrier materials against the contact metal needs to be controlled depending on the integration scheme. This paper focuses on understanding the barrier CMP process selectivity on the model W/Ti/TiN applications through electrochemical evaluations and chemically modified thin film analyses. Ex-situ electrochemical evaluations are conducted on the W/Ti/TiN system to evaluate the passivation rates in various slurry formulations as a function of the slurry chemistry and the abrasive particle solids loading. Results of the passivation rates are compared to the removal rate selectivity and the post CMP surface quality on blanked $\mathrm{W}, \mathrm{Ti}$, and TiN films. A new methodology for CMP slurry formulations through ex-situ electrochemical analyses is outlined for new and more challenging barrier films while simultaneously highlighting an approach for corrosion prevention on the metallic layers.

(C) The Author(s) 2019. Published by ECS. This is an open access article distributed under the terms of the Creative Commons Attribution Non-Commercial No Derivatives 4.0 License (CC BY-NC-ND, http://creativecommons.org/licenses/by-nc-nd/4.0/), which permits non-commercial reuse, distribution, and reproduction in any medium, provided the original work is not changed in any way and is properly cited. For permission for commercial reuse, please email: oa@electrochem.org. [DOI: 10.1149/2.0181905jss]
\end{abstract}

(cc) BY-NC-ND

Manuscript submitted February 11, 2019; revised manuscript received March 29, 2019. Published April 9, 2019. This paper is part of the JSS Focus Issue on CMP for Sub-10 nm Technologies.

The trend toward miniaturization of the microelectronics fabrication, particularly beyond $10 \mathrm{~nm}$ is resulting in a shift toward new interconnect architectures with unconventional materials introduced as barriers. In particular, copper-based metallization combined with low-k dielectrics has been challenging with a need to develop effective CMP processes and selection of consumables to enable device reliability. ${ }^{1}$ Copper interconnects meet the requirements of low resistivity, stability during processing and operation, improved electromigration performance and the ability to be deposited and etched functionally and effectively. $\mathrm{Cu}$ requires a high-performance barrier layer to enhance adhesion to underlying films as well as to stop any $\mathrm{Cu}$ ion diffusion to the transistors that will lead to their malfunction. Ta/TaN is being used in combination with the $\mathrm{Cu}$ interconnects with a twostep CMP process. Conventionally, the first step removes the bulk $\mathrm{Cu}$ layers and the second step removes the barrier layer, hard/soft masks and the dielectric film. ${ }^{2}$

As a new material, cobalt has been shown to improve the adherence of $\mathrm{Cu}$ to the barrier layers such as TaN, WN and TiN. Furthermore, $\mathrm{Co}_{4} \mathrm{~N}$ is a good candidate as a barrier material due to its similar FCC structure and small lattice mismatch with $\mathrm{Cu} .{ }^{3-5}$ Ruthenium is another alternative barrier material. Although it has a relatively higher lattice mismatch to $\mathrm{Cu}$, it gives better coverage and wettability. ${ }^{3}$ Manganese $(\mathrm{Mn})$ and Molybdenum $(\mathrm{Mo})^{9}$ are other alternatives since the $\mathrm{Ru}$ CMP generates a poisonous product at low $\mathrm{pH}$ values (lower than $\mathrm{pH}$ 8). Manganese (Mn) penetrates the silica in nano-scale and makes a barrier layer with high adhesion strength to $\mathrm{Cu}$ and hence it is considered as another good barrier layer alternative. ${ }^{6-8}$ Mo and its alloys such as CoMo are also effective barrier materials due to their passivation in aqueous media that can be controlled by adding surfactants. ${ }^{9}$ The selection of barrier and liner materials is also critical in satisfying the process integration requirements. In processing 10-nm technology, $\mathrm{Ru}$ meets the better gap fill requirements as a liner material over a TaN barrier. However, a recent CMP study showed the formation of $\mathrm{Ru}$ layer bending and $\mathrm{Cu}$ contact recess due to corrosion potential

*Electrochemical Society Member.

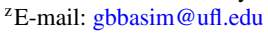

differences between the $\mathrm{Cu}$ and $\mathrm{Ru}$ metallic layers leading to variation in the CMP removal rates. ${ }^{6}$ Hence, the continuing challenges in planarization need to be addressed through understanding the selectivity requirements and introducing alternative slurry formulations.

Tungsten (W) contact or via fill has been well established in microelectronics applications with $\mathrm{Ti} / \mathrm{TiN}$ as the standard barrier/liner layer. ${ }^{10} \mathrm{Ti} / \mathrm{TiN}$ stack is an effective diffusion barrier to tungsten due to its thermal and chemical stability and the ability of passivation by creating an oxide layer that promotes adhesion. ${ }^{11}$ Besides, the Ti layer is used as an oxygen gettering layer for contacts as it reacts with the residual oxygen to reduce its content in a vacuum environment. TiN can also serve as an adhesion layer between the metal and the dielectric in the case of W contact as well as a barrier to prevent WF6 from reacting with the underlying Ti during the W CVD process. These layers help in electromigration protection for two reasons; (i) Ti/TiN stack shows superior barrier characteristics when compared to TiW; which was another barrier material in metallization of earlier VLSI based $\mathrm{Al}$ devices. It was observed that the interface reaction between TiW and Si layer was sensitive to the deposition temperature of the barrier metal, while W/Ti/TiN/Si was not, ${ }^{12}$ (ii) Ti/TiN stack also provides a better electro-migration lifetime performance than TiN process which forms a TiN-Ti compound from a multi-Ti-mono-N cluster. ${ }^{13}$ Tungsten plugs continue to be a critical part of process integration starting at $22 \mathrm{~nm}$ to connect the transistors and interconnects at the middle-of-line (MOL) processing. Particularly, the shrinking sizes of the plugs reduce the volume of tungsten, which results in increasing device resistance. Hence, the semiconductor industry is considering replacing the $\mathrm{W}$ plugs with the Co. ${ }^{14}$ Alternatively, the introduction of new $\mathrm{W}$ based material that can serve as both barrier and liner film is tested to allow the gap to be filled with more $\mathrm{W}$ rather than consuming the volume by the Ti/TiN layers. ${ }^{15}$

In this study, we established a systematic approach for comparing the chemical and mechanical compatibility of the W, Ti and TiN films representative of barrier CMP. The correlation between the formation of chemically modified layers and their removal by the slurry abrasive particles is well established on CMP removal rate selectivity. ${ }^{16}$ The chemically modified layers are typically passive metal-oxide nano-films in metal CMP applications. In earlier studies, we have 
demonstrated the formation of tungsten oxide and titanium oxide passive films and their effects on surface energy and topography for the CMP applications. ${ }^{17,18}$ Here, we extend these analyses to $\mathrm{W}$, Ti and TiN layers to investigate their corrosion behavior and passivation characteristics as a function of $\mathrm{H}_{2} \mathrm{O}_{2}$ (oxidizer) concentration. Electrochemical analyses indicate that the higher is the oxidizer concentration, the faster is the rate of passivation, which is further related to the increase in the material removal rates (MRR). Furthermore, it was observed that when the rate of passive layer formation was comparable for the different films, the removal rates were also comparable leading to the control of removal rate selectivity. Therefore, CMP slurry chemistry and slurry particle concentrations were tuned to enable $1: 1: 1$ removal rate selectivity of the W/Ti/TiN films to facilitate a single step planarization process.

Primarily, the chemical composition of the CMP process was optimized at the fixed slurry abrasive concentration by changing the oxidizer concentration. Removal rate selectivity was achieved at $0.2 \mathrm{M}$ oxidizer concentration, where $\sim 76 \mathrm{~nm} / \mathrm{min}$ MRR values were obtained for each film. Subsequently, the mechanical component of the CMP process was studied by changing the slurry abrasive concentration at the $0.2 \mathrm{M}$ (optimal) $\mathrm{H}_{2} \mathrm{O}_{2}$ concentration. It was observed that the tungsten CMP is more chemically controlled by the formation of the tungsten oxide film and less affected by the changes in the mechanical abrasions. Whereas, the Ti and TiN films showed more correlation to the mechanical activity when the abrasive concentration was changed. Post CMP surface roughness characterizations were also performed to assist in understanding the quality of the interface between $\mathrm{W} / \mathrm{Ti} / \mathrm{TiN}$ layers.

The ex-situ electrochemical evaluations presented in this paper are critical to control the material removal rate selectivity to provide Within-Die (WID) planarization uniformity. Once the CMP slurry chemistry is designed to enable the WID uniformity to enable the control of the local topography of the microprocessor layout, the advanced CMP tools (which are designed to tune the regional downforce on the polishing head) can be integrated with the adjustment of the pressure zones. Consequently, the ex-situ electrochemical evaluation based CMP selectivity optimization is also believed to help improve the Within-wafer (WIW) uniformity through better planarization for the $300 \mathrm{~mm}$ wafer manufacturing.

\section{Experimental}

Materials.-200mm CVD deposited tungsten, titanium and TiN wafers were obtained from Texas Instruments Inc. They were cut into square-shaped coupons of $10 \times 10 \mathrm{~mm}$ in size to conduct the electrochemical analyses and $14 \times 14 \mathrm{~mm}$ for the CMP experiments. All wafers were cleaned prior to the electrochemical tests, where $\mathrm{W}, \mathrm{Ti}$, and TiN coupons were immersed into DI water at $\mathrm{pH} 9$ and placed into an ultrasonic bath for 5 minutes to clean the native oxide on the surface. Hydrogen peroxide $\left(\mathrm{H}_{2} \mathrm{O}_{2}-\right.$ Sigma Aldrich, \%34.5-36.5 purity) was used as an oxidizer in the electrochemical tests as well as the CMP experiments at $0.1 \mathrm{M}, 0.2 \mathrm{M}, 0.3 \mathrm{M} 0.5$ and $1 \mathrm{M}$ concentration.

Methods.-Electrochemical measurements.-Potentiostatic transient and potentiodynamic polarization experiments were conducted by using the electrochemical cell setting shown in Figure 1. Blanked wafers of $\mathrm{W}, \mathrm{Ti}$ and $\mathrm{TiN}$ were connected in place of the working electrodes. Output signals were measured between the working and the counter electrodes in the cell. The counter and reference electrodes used in these measurements were platinum and SCE (Saturated Calomel Electrode), respectively. Gamry Interface 1000 Potentiostat was used along with the software of Gamry framework and the raw data was analyzed by using Gamry Echem Analyst software.

Potentiostatic (current versus time) transient experiments were set to collect data for a continuous duration of 1100 seconds. Input potential was set to a low value, which was close to zero Volts vs. $\mathrm{E}_{\mathrm{ref}}$ (the real value shown during the test were $\sim 90-100 \mu \mathrm{V}$, which was negligible and assumed to be zero). All the plates were immersed in deionized water at the beginning of the experiments before the mea-

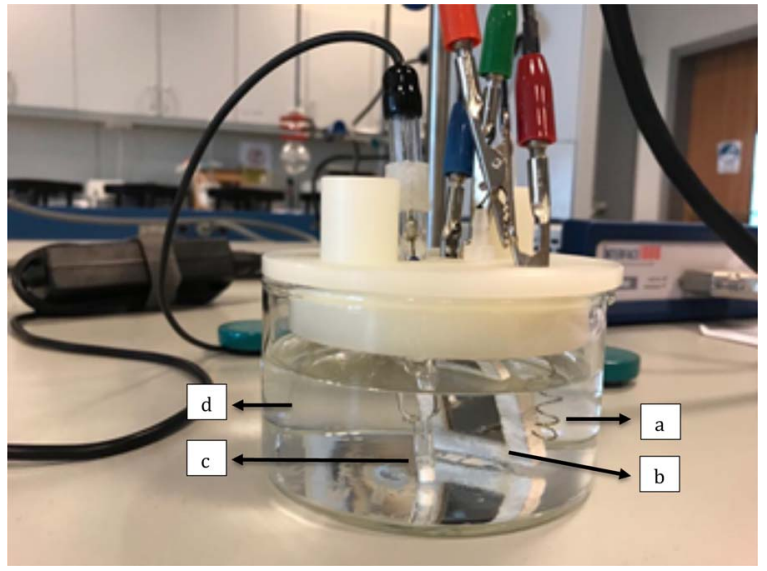

Figure 1. Electrochemical cell setting. (a) counter electrode, (b) working electrode, (c) reference electrode and (d) electrolyte solution.

surements were started. After a few seconds, $\mathrm{H}_{2} \mathrm{O}_{2}$ (diluted from a stock concentration of $35 \mathrm{wt} \%$ ) was added according to the desired molarity in the solution of the final volume of $150 \mathrm{ml}$. Finally, the samples were rinsed and dried with nitrogen to prepare the surfaces for post surface characterizations.

Potentiodynamic scans were performed on the $\mathrm{W}, \mathrm{Ti}$, and TiN wafer coupons in $\mathrm{H}_{2} \mathrm{O}_{2}$ solutions as before. Before starting the polarization scans, open circuit delay voltages were measured for 10 seconds. Potentiodynamic scan output signal (current $\mathrm{I}_{\mathrm{m}}$ ) was collected at a range from $-5 \mathrm{~V}$ to $8 \mathrm{~V}$ input potential with a scan rate of $50 \mathrm{mV} / \mathrm{s}$ and a step of $1 \mathrm{mV}$ for each point. The total scan period was around 30 minutes. The resultant curve was plotted as potential (Volts) versus log current (Amperes). Tafel data were calculated for each scan and used to determine the output parameters by the Gamry Echem Analyst software including; (i) the corrosion rate, (ii) the corrosion current $\left(\mathrm{I}_{\text {corr }}\right)$ and (iii) the electrochemical corrosion potential $\left(\mathrm{E}_{\mathrm{corr}}\right)$ which is a measure of the voltage difference between the wafers as the working electrodes and the standard reference electrode.

Surface characterization.-Wettability of surfaces relates to the surface energy and it is known to be affected by the surface chemistry as well as the surface nano/microtopography. Sessile drop method was used to conduct the contact angle measurements post potentiostatic scans on the wafer surfaces by using deionized water as the condensed liquid phase in the air. The size of the drops was maintained at $\sim 160 \mu \mathrm{m}$ and the KVS AttentionTheta Goniometer was used for the measurements. Before analyzing the wettability of the samples, wafer coupons were rinsed with ethanol and cleaned in DI water in an ultrasonic bath for 10 minutes and dried with nitrogen gas.

Atomic force microscopy by Nanomagnetics Instruments was utilized to quantify surface roughness. Surface topography images of the bulk titanium plates were generated by scanning in the contact mode. The scan area was set to $10 \times 10 \mu \mathrm{m}$ with a scan speed of $6 \mu \mathrm{m} / \mathrm{second}$. Minimum three measurements were taken for each sample to obtain an average root mean square (RMS) roughness value. The topographic images and their 3D and cross-sectional views were analyzed to validate the roughness values.

Chemical mechanical polishing experiments.-CMP experiments were conducted by using silica-based commercial CMP slurry with 3\%wt solids loading and IC1000/Suba IV stacked pad on a tabletop Tegrapol-31 polisher. Polishing was performed for 30 seconds, at a downforce of $30 \mathrm{~N}$ and a rotation speed of $150 \mathrm{rpm}$ for both the head and the platen. Hydrogen peroxide $\left(\mathrm{H}_{2} \mathrm{O}_{2}\right)$ was introduced as an oxidizer through a secondary slurry line at $0.1,0.2,0.3,0.5$ and $1 \mathrm{M}$ concentrations. After polishing, wafer coupons were cleaned with acetone and DI water in an ultrasonic bath for 10 minutes and dried with nitrogen gas. To determine the material removal rates, wafer samples 
were weighted pre and post CMP application. Measurements were conducted using a high precision balance (PrecisaGravimetrics) with an accuracy of $\pm 0.01 \mathrm{mg}$.

Initially, the CMP performances of all the W/Ti and TiN coupons were optimized with $3 \mathrm{wt} \%$ slurry solids loading by only varying the oxidizer concentration. A 1:1:1 removal rate selectivity was obtained for $\mathrm{W} / \mathrm{Ti} / \mathrm{TiN}$ at $0.2 \mathrm{M} \mathrm{H}_{2} \mathrm{O}_{2}$ addition at $3 \mathrm{wt} \%$ solids loading. To evaluate the impact of mechanical interactions, additional CMP experiments were conducted at $0.2 \mathrm{M}$ oxidizer concentration by changing the slurry solids loading from $3 \% \mathrm{wt}$ to $5 \%, 10 \%$, and $15 \mathrm{wt} \%$. The baseline silica slurry with $30 \%$ wt solids concentration was diluted with $\mathrm{pH}$-adjusted water (at pH 9) to modify the solids loadings.

\section{Results and Discussion}

Tungsten, titanium and TiN blanket wafers were used as square coupons for the electrochemical measurements and the CMP experiments. Initially, potentiodynamic measurements were conducted as a function of oxidizer concentration to determine the surface corrosion rates as an indication of the chemically modified thin formation. Next, the surface passivation behaviors of the three films were measured by the potentiostatic scans to evaluate the rate of passivation. Surface wettability and roughness values were analyzed in parallel to the electrochemical measurements. The results of the electrochemical analyses were compared to the CMP material removal rate (MRR) responses on $\mathrm{W} / \mathrm{Ti} / \mathrm{TiN}$ films as a function of the slurry oxidizer concentration and slurry solids loading variation.

Electrochemical evaluations on W/Ti/TiN blanket wafers.Potentiodynamic measurements.-Figures $2 \mathrm{a}, 2 \mathrm{~b}$, and $2 \mathrm{c}$ illustrate the potentiodynamic polarization responses of the $\mathrm{W}$, Ti and TiN films in $0.1,0.2,0.3,0.5$ and $1 \mathrm{M} \mathrm{H}_{2} \mathrm{O}_{2}$ media, respectively. In the presence of hydrogen peroxide at selected concentrations all the curves showed a similar cathodic response. The measured current on the film surfaces decreased as the applied potential reached the zero value and started progressing into the anodic polarization portion of the curve. Passivation currents were observed at zero potential levels for each oxidizer concentration on all three films. The lowest zero potential conductivity was observed at $0.1 \mathrm{M}$ on tungsten wafer. The scanned curves were similar for all the concentrations other than the $1 \mathrm{M} \mathrm{H}_{2} \mathrm{O}_{2}$ addition, where uncontrollable corrosion was observed on the wafer. The titanium films showed the lowest passivation current at the $0.2 \mathrm{M}$ of $\mathrm{H}_{2} \mathrm{O}_{2}$ addition (Figure $2 \mathrm{~b}$ ), and both Ti and TiN had similar passivation currents at all the selected concentrations of the oxidizer, yet a more pronounced variability was observed on TiN as can be seen in Figure 2c.

Table I summarizes the Tafel data calculations for the selected films at the given oxidizer concentrations. Tungsten showed relatively low corrosion rates up to $0.5 \mathrm{M} \mathrm{H}_{2} \mathrm{O}_{2}$ addition, whereas, a high rate of $3.7 \mathrm{~mm} /$ year was observed at $1 \mathrm{M}$. This phonemenon is further illustrated in Figure 3 as a sharp increase in the corrosion rate with the image of the corroded W wafer coupon. Titanium wafers showed much consistent corrosion rate behavior irrespective of the oxidizer concentration. This can be attributed to the protective nature of the titanium oxide surface layer that is consistently effective even at the $1 \mathrm{M} \mathrm{H}_{2} \mathrm{O}_{2}$ addition. ${ }^{18}$ In the case of TiN films, Tafel data showed higher corrosion rate values as compared to titanium and tungsten. An increase was observed in the corrosion rate at $1 \mathrm{M}$ oxidizer addition similar to tungsten. TiN is considered to be more of a ceramic material in its chemical nature and oxidizes into $\mathrm{TiO}_{2}$ in the presence of oxygen or at high temperatures. ${ }^{19}$ Furthermore, it has a rock salt $(\mathrm{NaCl})$ crystal structure with lower atomic packing and titanium that can explain its poorer passivation performance. At the relatively higher concentrations of the oxidizer, the oxidation process became more unpredictable. Yet, titanium and TiN can be considered as suitable liner and barrier layers for $\mathrm{W}$ at the lower $\mathrm{H}_{2} \mathrm{O}_{2}$ concentrations. Since the TiN is the liner at the interface with the dielectric substrate, it also serves as a transition material from the dielectric to the interconnecting conductor and hence its ceramic like nature better suits the interface.

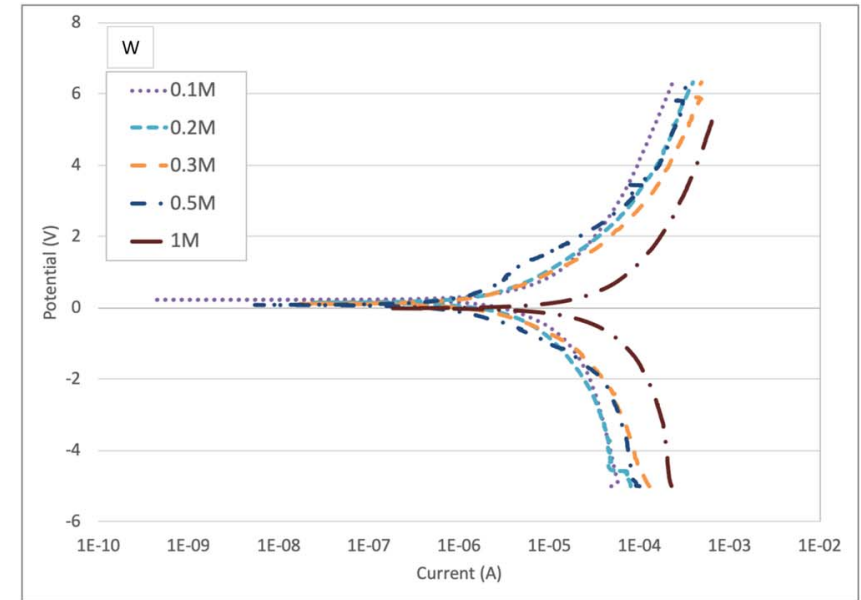

(a)

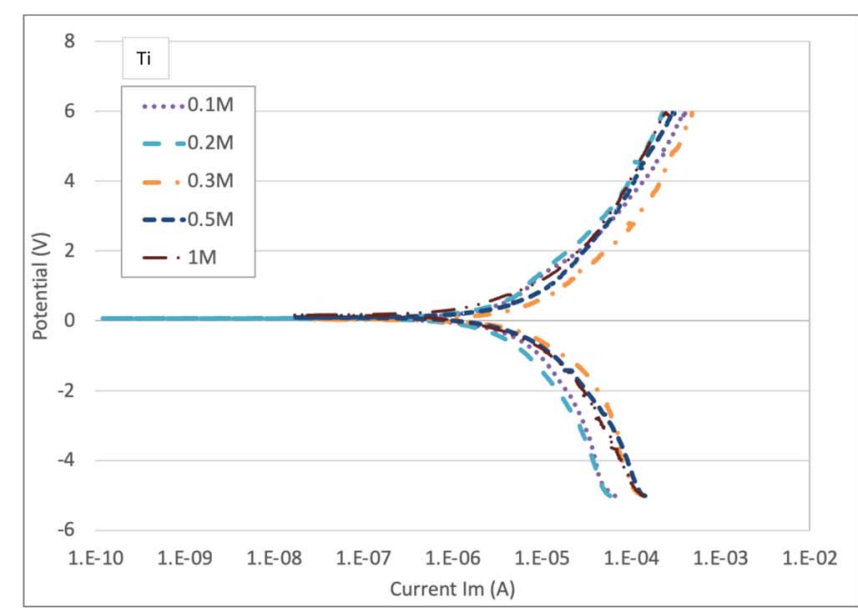

(b)

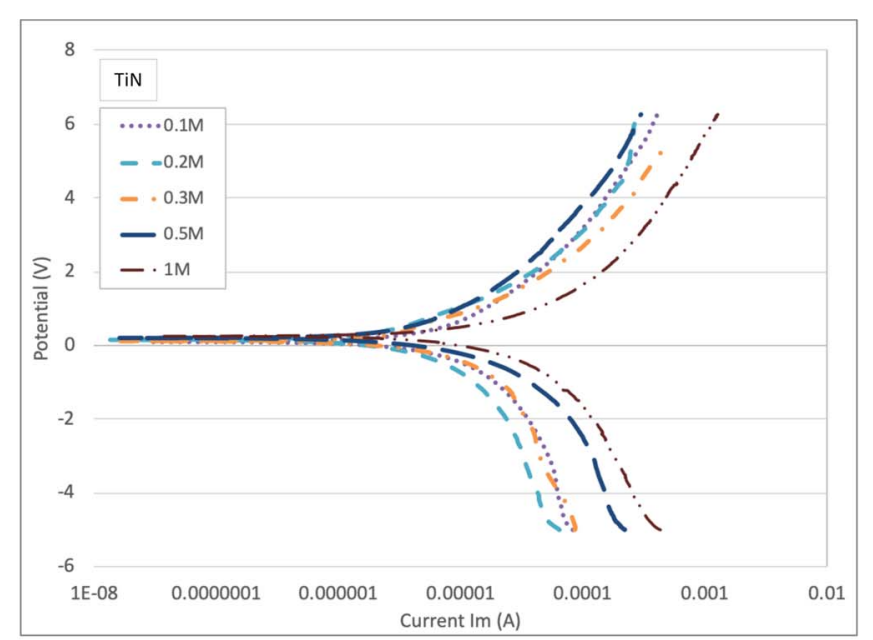

(c)

Figure 2. Potentiodynamic curves of (a) tungsten (W), (b) yitanium (Ti) and (c) titanium nitride (TiN) deposited wafers in the presence of $0.1,0.2,0.3,0.5$ and $1 \mathrm{M} \mathrm{H}_{2} \mathrm{O}_{2}$ in the solution added as an oxidizer.

Potentiostatic transient measurements.-Figures $4 \mathrm{a}, 4 \mathrm{~b}$ and $4 \mathrm{c}$ show the current versus time transient measurements of W, Ti and TiN wafers immersed in hydrogen peroxide solutions at the $0.1,0.2,0.3,0.5$ and $1 \mathrm{M}$ concentrations. The AFM micrographs of the surfaces exposed to the varying concentrations of the oxidizer are also illustrated for the corresponding concentrations. It can be seen in Figure 4a that, on 
Table I. Summary of Tafel data and corrosion rates of W, Ti and TiN as a function of oxidizer $\left(\mathrm{H}_{2} \mathrm{O}_{2}\right)$ concentration at $0.1,0.2,0.3,0.5$ and $1 \mathrm{M}$.

\begin{tabular}{|c|c|c|c|c|c|c|}
\hline & & \multicolumn{5}{|c|}{$\mathrm{H}_{2} \mathrm{O}_{2}$ Concentration } \\
\hline Tafel Variables & & $0.1 \mathrm{M}$ & $0.2 \mathrm{M}$ & $0.3 \mathrm{M}$ & $0.5 \mathrm{M}$ & $1 \mathrm{M}$ \\
\hline Icorr $(\mu \mathrm{A})$ & $\mathrm{W}$ & 25.90 & 12.10 & 9.930 & 3.950 & $192,0 \mathrm{e}-6$ \\
\hline Ecorr (mV) & & 227.0 & 148.0 & 113.0 & 82.30 & $-14,50$ \\
\hline Corrosion Rate (mm/yr) & & 0.249 & 0.116 & 0.095 & 0.038 & 3.696 \\
\hline $\operatorname{Icorr}(\mu \mathrm{A})$ & $\mathrm{Ti}$ & $3.8 \mathrm{e}-6$ & $3.5 \mathrm{e}-6$ & $9.8 \mathrm{e}-6$ & $5.810 \mathrm{e}-6$ & $3.850 \mathrm{e}-6$ \\
\hline Ecorr $(\mathrm{mV})$ & & 63.20 & 71.30 & 38.70 & 96.50 & 168.0 \\
\hline Corrosion Rate (mm/yr) & & 0.0767 & 0.0699 & 0.1964 & 0.1159 & 0.0768 \\
\hline Icorr $(\mu \mathrm{A})$ & $\mathrm{TiN}$ & $12.70 \mathrm{e}-6$ & $12.3 e-6$ & $14.6 \mathrm{e}-6$ & $7.78 \mathrm{e}-6$ & $26.6 \mathrm{e}-6$ \\
\hline Ecorr (mV) & & 96.90 & 149.0 & 114.0 & 200.0 & 246.0 \\
\hline Corrosion Rate (mm/yr) & & 0.514 & 0.462 & 0.547 & 0.3106 & 1.076 \\
\hline
\end{tabular}

the $\mathrm{W}$ surface, there is a decrease in the current toward the negative values indicating surface oxidation in the first $\sim 100$ seconds of oxidizer exposure. A steady-state current value is obtained afterwards. This observation only differs for the $1 \mathrm{M} \mathrm{H}_{2} \mathrm{O}_{2}$ addition, where severe corrosion was observed on the $\mathrm{W}$ wafer coupon (Figure 3). Although there was an initial passive film formation, the current flow continued to increase abruptly after approximately 50 seconds of dipping. Based on our earlier studies, we have demonstrated that the oxidation of $\mathrm{W}$ is driven by the nucleation and growth mechanisms controlled by the Oswald ripening on the surface. ${ }^{20}$ Furthermore, the surface oxide structures and the roughness correlate to the CMP removal rate and defectivity performance. ${ }^{17}$ The passive film formation was confirmed by the X-Ray Reflectivity measurements and the Pilling-Bedworth ratio calculations. The AFM images taken on the passivated $\mathrm{W}$ surfaces align with the proposed nucleation and growth mechanisms as it is further discussed in the next section. It must be noted that since the frequency of the surface abrasion during the CMP is very fast $(\sim 1000$ particles/second), even at the $1 \mathrm{M}$ oxidizer concentration a sufficient surface oxide is present to be removed from the perspective of the CMP operational conditions. ${ }^{17}$

Figures $4 \mathrm{~b}$ and $4 \mathrm{c}$ demonstrate the current steady state behavior as a function of the oxidizer concentration on the titanium and titanium nitride wafer coupons, respectively. On both of these films, the passivation currents also became more negative as a function of the increasing oxidizer concentration. Corrosion rates remained less than $0.1 \mathrm{~mm} /$ year on $\mathrm{Ti}$, whereas the TiN showed higher corrosion rate responses at all the selected oxidizer concentrations $(\sim 0.5 \mathrm{~mm} /$ year $)$ and corroded faster at $1 \mathrm{M}(1.1 \mathrm{~mm} / \mathrm{year})$ as shown in Figure 3. It is known that Ti forms its protective film that is pore-free and continuous. The earlier studies conducted on Ti CMP have also confirmed the formation of the $\mathrm{TiO}_{2}$ film as a function of hydrogen peroxide at the acidic

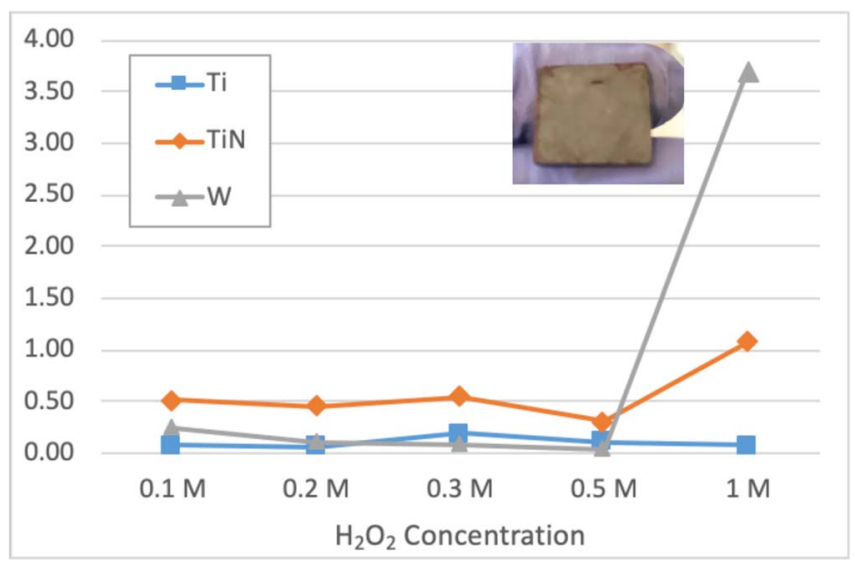

Figure 3. Corrosion rate values on $\mathrm{Ti}, \mathrm{TiN}$, and $\mathrm{W}$ wafers calculated based on potentiodynamic measurements of Tafel data as a function of oxidizer concentration.
pH ranges by XPS verification..$^{10,18,21-22}$ The surface micrographs collected on the Ti wafers also illustrated the nucleation of oxide peaks (Figure 4b), which is in agreement with the literature. ${ }^{21}$ TiN wafer coupons showed a lower surface conductivity than the Ti films, which can be attributed to TiN being more like a ceramic material in nature. Hence, it is generally expected to passivate less than the metals. Furthermore, the surface micrographs taken on the TiN wafer coupons as a function of the oxidizer addition do not show much variation or signs of oxide nucleation on the surface.

The rate of surface passive film formation.-The rate of oxide growth is important to evaluate material removal rates in CMP since the formation of surface oxide enables the material removal by the abrasive particles. Ti coupons showed relatively lower passivation currents as compared to $\mathrm{W}$, which aligns with the fact that the oxide film of $\mathrm{Ti}$ is self-protective and more stable than the tungsten oxide. $\mathrm{TiO}_{2}$ on $\mathrm{Ti}$ typically has a better surface coverage than the $\left(\mathrm{WO}_{3}\right)$ film formed on the $\mathrm{W}$ surface. ${ }^{21} \mathrm{TiN}$ as a non-metallic film, on the other hand, behaves differently with more negative passivation currents achieved as compared to $\mathrm{W}$ as well as Ti.

The rate of passive film formation, which is a function of the nucleation and growth of the oxide films, was observed to be different for the selected films. There is a tendency of a faster decay in the current toward negative values with the increasing oxidizer concentrations irrespective of the material chosen. In order to determine the rate of passive film formation, the decrease in the current flow per unit time was calculated for the $\mathrm{W}, \mathrm{Ti}$ and $\mathrm{TiN}$ coupons. Figure 5 shows the calculated oxidation rates in A/s at the $0.1,0.2,0.3,0.5$ and $1 \mathrm{M} \mathrm{H}_{2} \mathrm{O}_{2}$ concentrations for each wafer type. The increase in the oxidation rates suggests faster surface oxide formation, which aligns with the fact that there is more oxidizer available close to the substrate surface at the higher molarities. Consequently, faster nucleation and growth is promoted. At 0.1 and $0.2 \mathrm{M}$ oxidizer concentrations, the passivation rate values were similar in agreement with the observed corrosion rates. The only deviation from this trend was observed for $\mathrm{W}$ at $1 \mathrm{M} \mathrm{H}_{2} \mathrm{O}_{2}$ addition. At this condition there was an initial fall followed by the sharp rise in current toward corrosion currents. It can also be seen in Figure 5 that the $\mathrm{Ti}$ and $\mathrm{TiN}$ had a more pronounced change in the rate of oxidation as a function of the increasing oxidizer concentrations. This trend is also in agreement with the change in passivation currents of W, Ti and TiN shown in Figures 4a through 4c. The increase in the metal oxide formation rate has also been demonstrated in the literature as the exponents in MacDonald's model for the anodic passive films. ${ }^{23}$ It is expected that the closer the rates of passivation/oxide film formation on the integrated films, the better is the compatibility of the films to enable desired material removal rate selectivity.

Surface quality evaluation of W/Ti/TiN blanket films post electrochemical measurements. - Figure 6a illustrates the root mean square (RMS) roughness values obtained on the $\mathrm{W}, \mathrm{Ti}$, and TiN wafer coupons after the electrochemical analyses. The results correlate to the corrosion values showing an increase in the $\mathrm{W}$ surface roughness above the $0.5 \mathrm{M}$ concentration with $20 \mathrm{~nm}$ roughness at the $1 \mathrm{M} \mathrm{H}_{2} \mathrm{O}_{2}$ addition. This is related to the unstable surface nature of the oxide film leading to a more porous surface nature as it corrodes. While a more uniform layer 


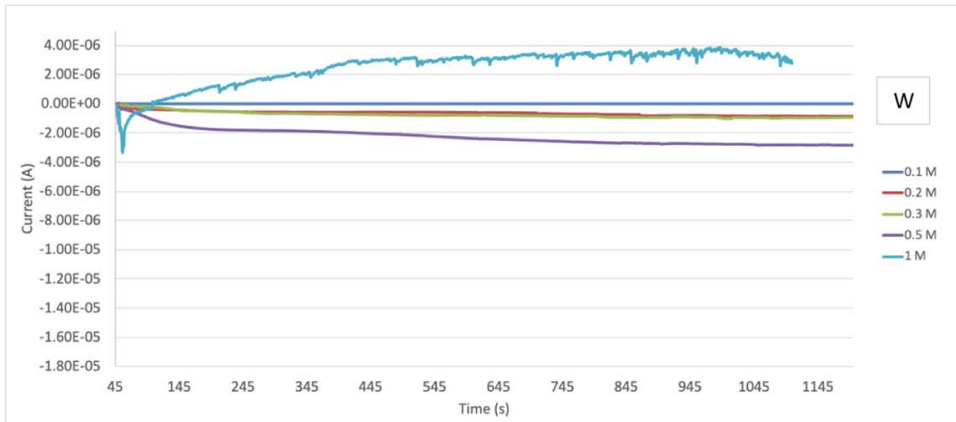

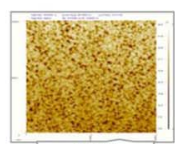

$0.1 \mathrm{M}$

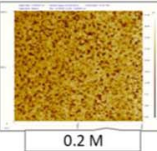

$0.2 \mathrm{M}$

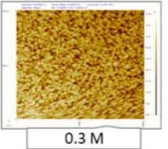

(a)

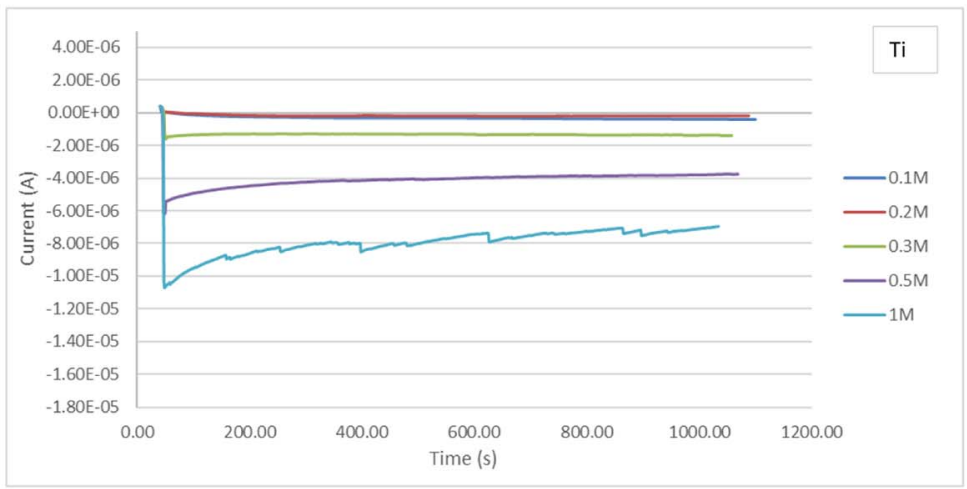

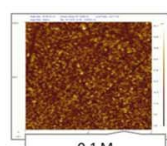

$0.1 \mathrm{M}$

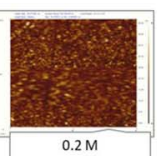

$0.2 \mathrm{M}$

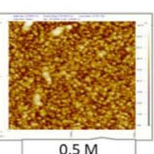

$0.5 \mathrm{M}$

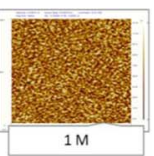

$1 \mathrm{M}$

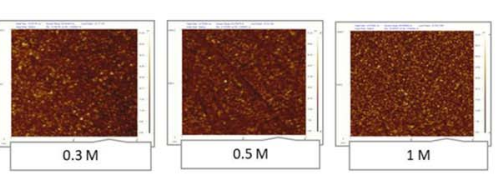

(b)

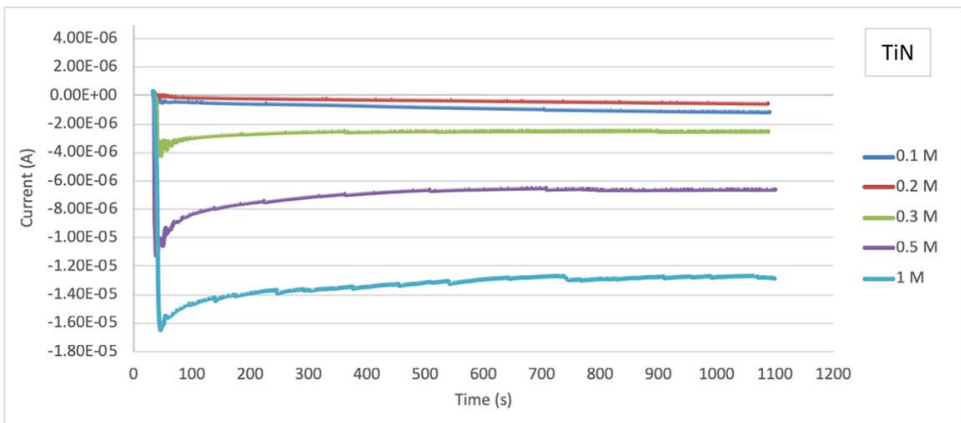

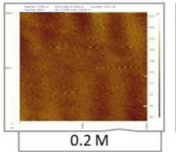

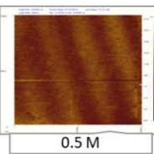

$0.5 \mathrm{M}$

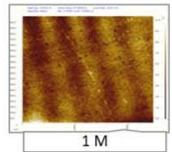

$1 \mathrm{M}$

(c)

formation was observed with reduced roughness values at the low concentrations, at $0.5 \mathrm{M}$ and $1 \mathrm{M}$ oxidizer addition surface quality degraded significantly. Titanium showed similar RMS roughness values for concentrations within $0.1 \mathrm{M}$ to $0.3 \mathrm{M}$ and, similar to $\mathrm{W}$, a relative increase was observed in the surface roughness at higher concentra-
Figure 4. Potentiostatic curves of (a) W, (b) Ti and (c) TiN deposited wafers at $0.1,0.2,0.3,0.5$ and $1 \mathrm{M} \mathrm{H}_{2} \mathrm{O}_{2}$ concentrations with corresponding AFM surface micrographs. 


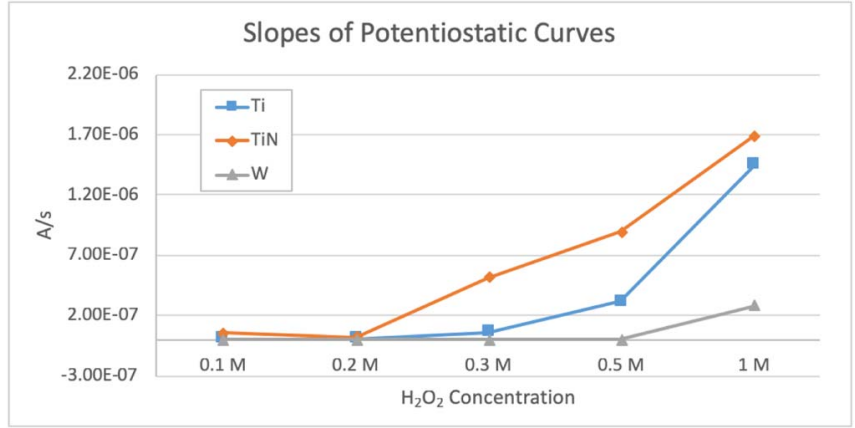

Figure 5. Potentiostatic passivation slopes calculated in $\mathrm{A} / \mathrm{s}$ for $\mathrm{W}, \mathrm{Ti}$, and TiN wafers as a function of $\mathrm{H}_{2} \mathrm{O}_{2}$ concentration.

TiN oxidation is different from the $\mathrm{W}$ and $\mathrm{Ti}$ as it is not a metallic material.

The surface wettability values measured with the contact angle method also showed variability on the tungsten surface as can be seen in Figure 6b. The relationship of the contact angle with the surface energy has been shown in the literature ${ }^{24}$ with a close relationship to the material removal rate response during the CMP applications. ${ }^{25,26}$ The contact angle values can be evaluated as a measure of the surface wettability and indicator of the surface energy. Wettability values were more variable on the $\mathrm{W}$ coupons as a function of the oxidizer concentration as compared to Ti and TiN films. Both $\mathrm{Ti}$ and TiN films were observed to give high contact angles as can be seen in Figure 6b. Although the measured contact angles of the TiN surfaces were slightly higher, the main change in the wettability responses was not statistically significant in between the two films. While hydrophobic behavior was observed on both $\mathrm{Ti}$ and TiN with very reproducible 100 degrees of contact angle values were measured, W wafers were observed to be more hydrophilic. Contact angle values of between 50 and 80 degrees were recorded on W, except for $1 \mathrm{M}$ concentration when the angle exceeded this range. This result indicates a change in the surface wettability and shows that the hydrophobicity increases when the surface is corroded and simultaneously more rough as compared to the lower concentrations of the oxidizer. This observation can be attributed to the increased surface roughness resulting in more air pockets getting trapped on the surface of the wafer and hence the measurement of a higher contact angle value.

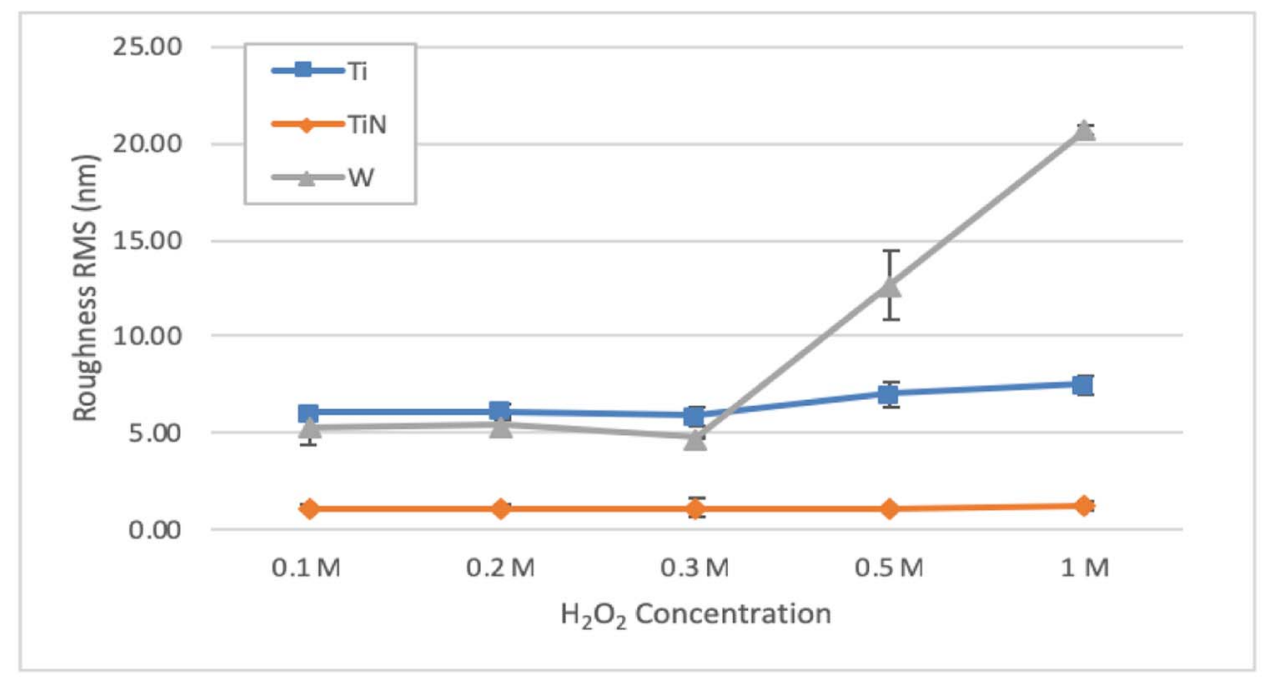

(a)

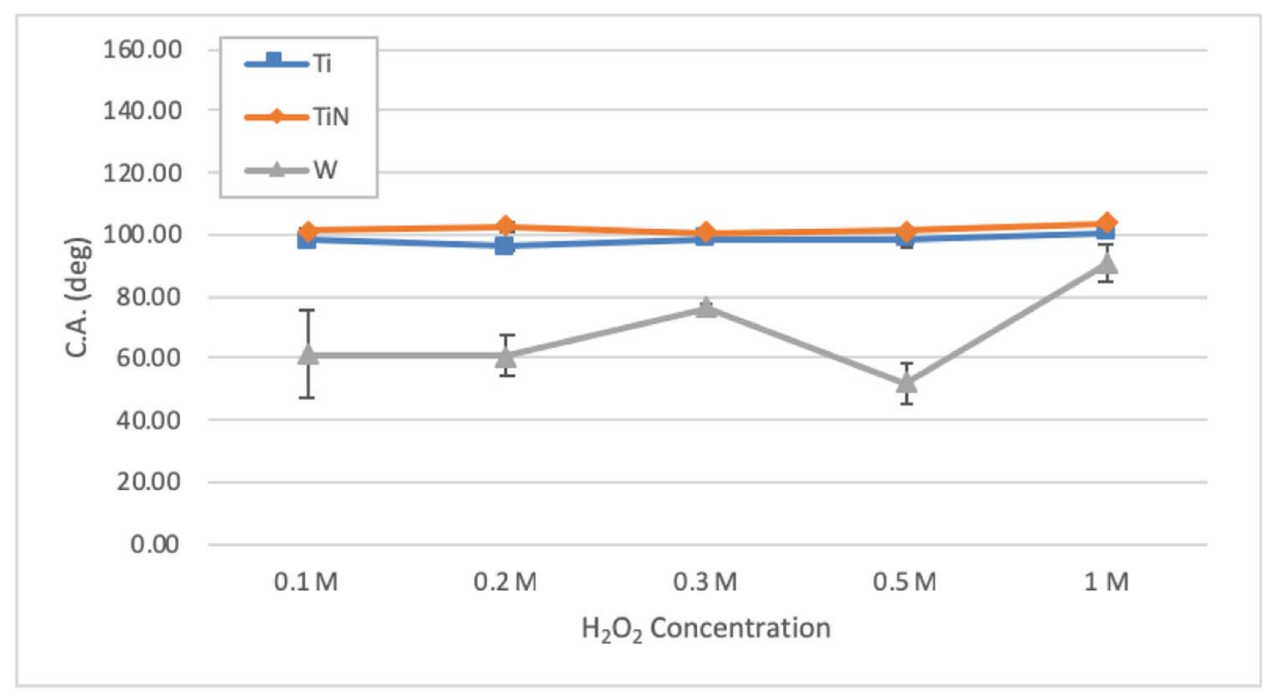

(b)

Figure 6. (a) RMS roughness values and (b) contact angle measurement results on W Ti, and TiN films post potentiostatic scans at different $\mathrm{H}_{2} \mathrm{O}_{2}$ concentrations. 


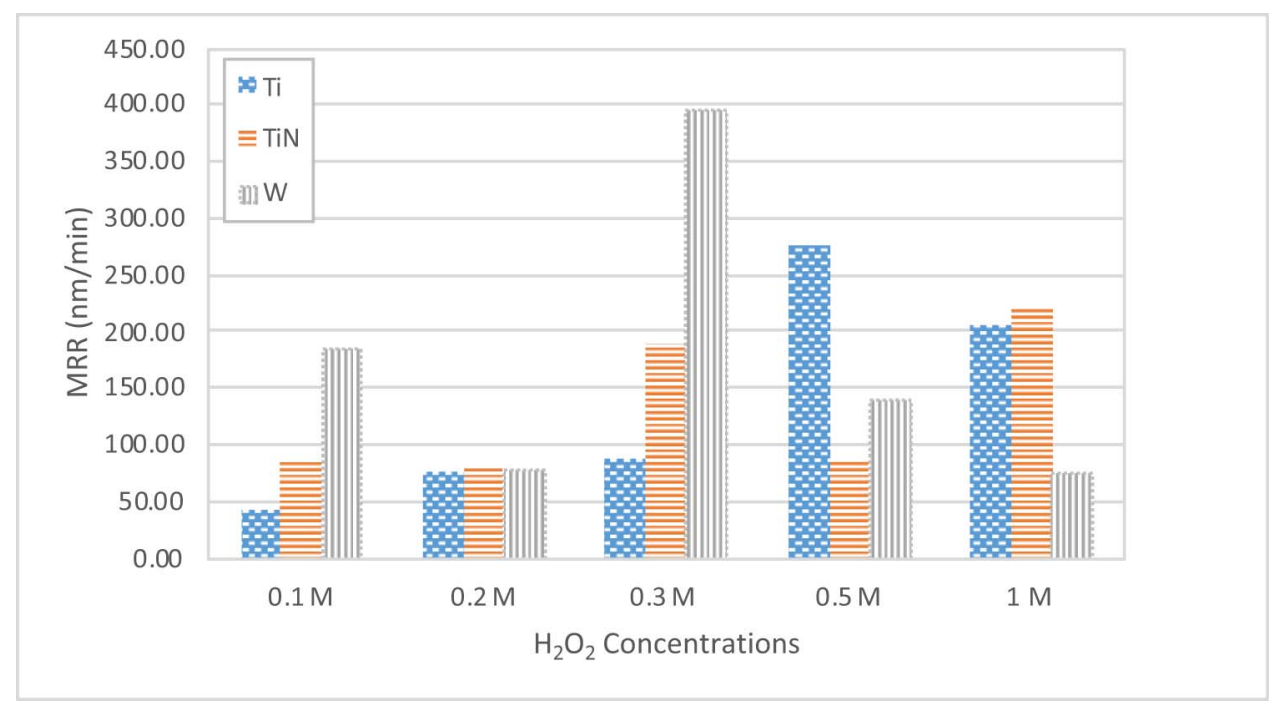

Figure 7. CMP material removal rates for Ti, TiN, and $\mathrm{W}$ wafers at $0.1,0.2,0.3,0.5$ and $1 \mathrm{M} \mathrm{H}_{2} \mathrm{O}_{2}$ concentrations by using 3 wt $\%$ solids loading CMP slurry.

Chemical mechanical polishing and selectivity evaluations.Effect of chemically modified thin films on CMP performance.-CMP performance evaluations were performed initially as a function of slurry chemical modification by changing the oxidizer concentration and maintaining the mechanical component constant. Figure 7 illustrates the material removal rates obtained on the W, Ti and TiN coupons as a function of oxidizer concentration after CMP with the $3 \mathrm{wt} \%$ solids loading silica slurry. Tungsten showed an irregular removal rate behavior along the selected concentrations. This can be attributed to the variability in the corrosion and passivation behavior of the $\mathrm{WO}_{3}$ aligning with our earlier studies. ${ }^{20}$ Titanium MRR values, on the other hand, showed an increase with the increasing $\mathrm{H}_{2} \mathrm{O}_{2}$ in the formulated slurries. This can be explained by the faster rate of passive film formation for $\mathrm{Ti}$ as represented in Figure 5. TiN wafers followed a similar trend with $\mathrm{Ti}$, which is also in agreement with the rate of passive film formation. Table II summarizes the MRR values and the selectivity obtained at the $0.1,0.2,0.3,0.5$ and $1 \mathrm{M}$ concentrations of the oxidizer for $\mathrm{W} / \mathrm{Ti} / \mathrm{TiN}$ films, respectively. It can be seen that at $0.2 \mathrm{M}$ oxidizer addition, suitable slurry settings were achieved to enable 1:1:1 MRR selectivity. This observation is also in arrangement with the closest values obtained for the rate of passivation in Figure 6 at the $0.2 \mathrm{M}$ concentration. Figures $8 \mathrm{a}$ and $8 \mathrm{~b}$ illustrate the observed surface quality in terms of roughness and wettability, respectively. It can be seen that post CMP surface roughness values were higher for the $\mathrm{W}(8-9 \mathrm{~nm})$ and the Ti $(7-8 \mathrm{~nm})$ surfaces while the TiN surface was smoother with $\sim 0.7 \mathrm{~nm}$ RMS roughness. Surface wettability responses, on the other hand, were similar to pre-CMP values for tungsten wafers. Yet, both $\mathrm{Ti}$ and $\mathrm{TiN}$ surfaces showed reduced contact angles indicating a more wettable surface was formed after CMP indicating a change in the surface energy by the exposure of the fresh surface layers as well as the change in the surface roughness. Overall, the average rough-

Table II. CMP material removal rate and selectivity results of $W$, $\mathrm{Ti}$ and TiN wafers as a function of slurry oxidizer concentration at $3 w t \%$ slurry solids loading.

\begin{tabular}{ccccc}
$\mathrm{H}_{2} \mathrm{O}_{2}$ Concentration & $\begin{array}{c}\mathrm{W} \text { MRR } \\
(\mathrm{nm} / \mathrm{min})\end{array}$ & $\begin{array}{c}\text { Ti MRR } \\
(\mathrm{nm} / \mathrm{min})\end{array}$ & $\begin{array}{c}\text { TiN MRR } \\
(\mathrm{nm} / \mathrm{min})\end{array}$ & $\begin{array}{c}\text { Selectivity } \\
(\mathrm{W} / \mathrm{Ti} / \mathrm{TiN})\end{array}$ \\
\hline $0.1 \mathrm{M}$ & 184.09 & 41.82 & 83.48 & $1 / 0.2 / 0.5$ \\
$0.2 \mathrm{M}$ & 76.40 & 74.94 & 79.16 & $1 / 1 / 1$ \\
$0.3 \mathrm{M}$ & 396.05 & 86.53 & 188.40 & $1 / 0.2 / 0.5$ \\
$0.5 \mathrm{M}$ & 140.22 & 275.54 & 88.27 & $1 / 2 / 0.6$ \\
$1 \mathrm{M}$ & 73.27 & 204.68 & 221.88 & $1 / 2.8 / 3$
\end{tabular}

ness values of TiN surfaces remained relatively lower as compared to $\mathrm{Ti}$ and $\mathrm{W}$, which can be explained based on different mechanisms of chemically modified surface film formation.

Effect of mechanical component on CMP performance.-Another important input to the chemical mechanical polishing process is the control of the slurry mechanical component, which is typically studied by changing the slurry abrasive concentration. The number of abrasive particles, which are actively engaging in CMP is critical to determine the amount of time the surface can grow an oxide film in between the abrasions. The abrasive particles provide the mechanical action in between the polishing pad and the wafer sample, and their frequency of interacting with the wafer surface determines the time to grow the chemically modified layer. ${ }^{20}$ Since a $1 / 1 / 1$ selectivity was obtained at $0.2 \mathrm{M}$ oxidizer concentration at $3 \mathrm{wt} \%$ slurry solids loading, the slurry solids concentrations were varied at 5, 10 and $15 \mathrm{wt} \%$ at the optimal oxidizer concentration of $0.2 \mathrm{M}$. Figure 9 shows the MRR values of $\mathrm{W}, \mathrm{Ti}$, and TiN as a function of slurry solids loading. Furthermore, Table III summarizes the obtained removal rates and the calculated selectivity values. Tungsten showed stable material removal rates across the selected slurry solids loading percentages. This result supports the observations that the chemical surface oxide formation regulates and controls the material removal for tungsten material. Surface roughness values were higher for $\mathrm{W}$ as can be seen in Figure 10a and the surface quality was poor as illustrated in the AFM micrographs in Figure 10b. Titanium, on the other hand, experienced a sudden increase in the removal rates at 5\% solids loading, which descended along the higher silica solids loading concentrations. The change in the removal rates indicates that the stable and self-protective titania layer is removed faster as the number of particles increases from 3 to $5 \%$ by occupying a larger surface area, yet at the further increased solids concentrations there is lower pressure per particle and hence a reduction in the MRR. This mechanism is also confirmed by the

\footnotetext{
Table III. CMP material removal rate and selectivity results of $\mathrm{W}$, $\mathrm{Ti}$ and TiN wafers as a function of slurry solids loading at $0.2 \mathrm{M}$ $\mathrm{H}_{2} \mathrm{O}_{2}$ addition.
}

\begin{tabular}{ccccc}
$\begin{array}{c}\text { Slurry Solids } \\
\text { Loading (wt\%) }\end{array}$ & $\begin{array}{c}\text { W MRR } \\
(\mathrm{nm} / \mathrm{min})\end{array}$ & $\begin{array}{c}\text { Ti MRR } \\
(\mathrm{nm} / \mathrm{min})\end{array}$ & $\begin{array}{c}\text { TiN MRR } \\
(\mathrm{nm} / \mathrm{min})\end{array}$ & $\begin{array}{c}\text { Selectivity } \\
(\mathrm{W} / \mathrm{Ti} / \mathrm{TiN})\end{array}$ \\
\hline 3 & 76.40 & 74.94 & 79.16 & $1 / 1 / 1$ \\
5 & 113.97 & 235.01 & 85.60 & $1 / 2 / 0.5$ \\
10 & 118.07 & 147.11 & 44.83 & $1 / 1.3 / 0.8$ \\
15 & 112.57 & 97.13 & 184.30 & $1 / 09 / 1.2$
\end{tabular}




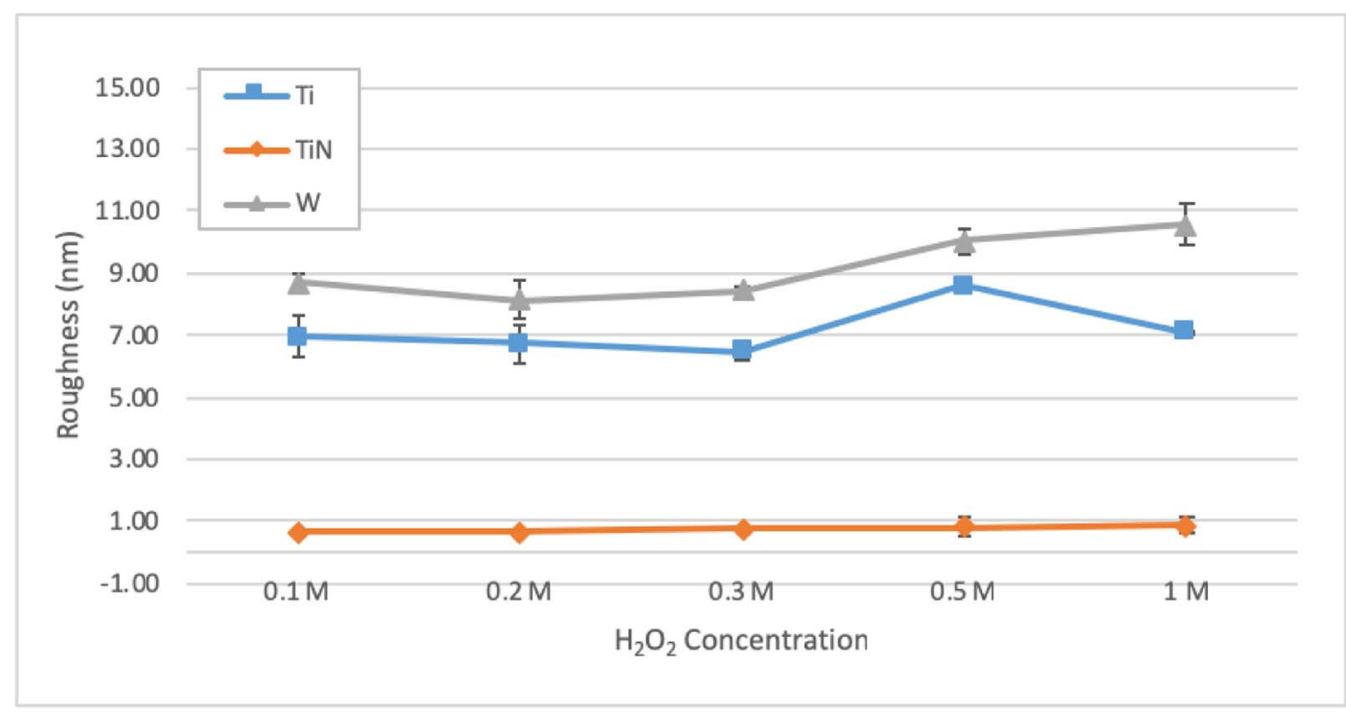

(a)

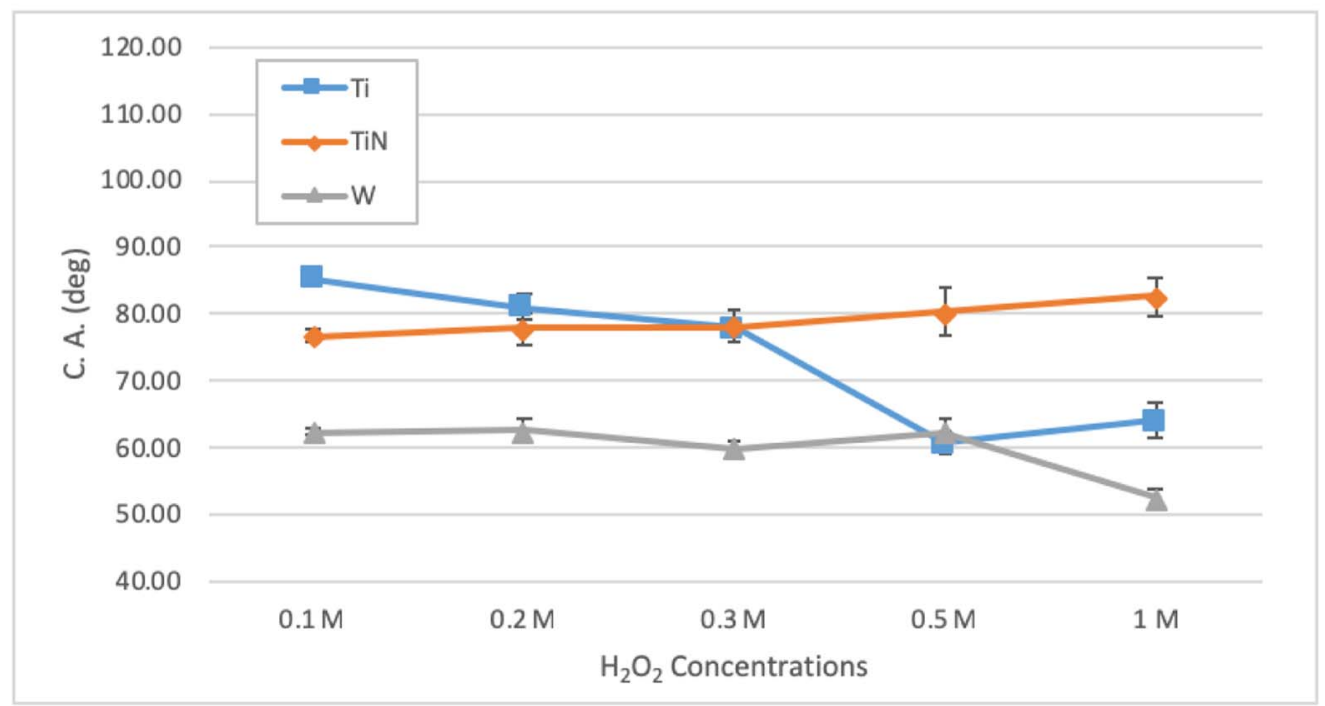

(b)

Figure 8. (a) RMS surface roughness values and (b) contact angle measurements on W, Ti, TiN films as a function of $\mathrm{H}_{2} \mathrm{O}_{2}$ concentrations post CMP process with $3 \mathrm{wt} \%$ slurry solids loading.

reduction in the surface roughness values on the Ti film at 10 and $15 \mathrm{wt} \%$ solids loadings as can be seen in Figure 10a and observed surface scratches on the AFM micrographs of Figure 10b. TiN film, however, demonstrated lower MRR values with much lower surface roughness $(\sim 1 \mathrm{~nm})$. A slight increase in the roughness with the increasing solids loading was observed on TiN indicating a more mechanically inclined material removal mechanism at higher solids loadings. Although the change in the slurry solids loadings affected the MRR values of the $\mathrm{W}, \mathrm{Ti}$ and TiN films, a 1/1/1 selectivity was only obtained at the $3 \mathrm{wt} \%$ solids loading and $0.2 \mathrm{M}$ oxidizer concentration. Yet, it can be seen that the MRR selectivity can be tuned by changing both the chemical and the mechanical components of the CMP process and controlling the ex-situ electrochemical behavior in parallel.

\section{Conclusions}

The new interconnect integration schemes for the sub-10 nm technology require the selection of thermally and chemically stable barrier layers and their effective planarization through the control of material removal selectivity during the CMP process. In this paper, electro- chemical analyses of metal and barrier films were explored as a function of oxidizer concentration through potentiodynamic and potentiostatic methods on a model W/Ti/TiN system. The Tafel data obtained from the potentiodynamic scans showed that the corrosion rates of the $\mathrm{W}, \mathrm{Ti}$ and TiN films remained similar from $0.1 \mathrm{M}$ to $0.5 \mathrm{M} \mathrm{H}_{2} \mathrm{O}_{2}$ concentration and accelerated at $1 \mathrm{M}$ concentration. Furthermore, the potentiostatic sweeps showed passivation of the surfaces indicating the formation of chemically modified oxide layers. The initial passivation slopes were stable up to $0.2 \mathrm{M} \mathrm{H}_{2} \mathrm{O}_{2}$ concentration. Hence an optimal $0.2 \mathrm{M}$ oxidizer addition was selected for the slurry formulation, which also resulted in a relatively low value of corrosion on $\mathrm{W}, \mathrm{Ti}$ and $\mathrm{TiN}$, measured to be $0.12,0.07$ and $0.46 \mathrm{~mm} /$ year, respectively. TiN film as a non-metallic layer showed higher corrosion rates due to natural porosity, yet better surface roughness since the mechanism of surface film formation is different. The surface roughness values were higher on $\mathrm{W}$ and Ti films at $0.5 \mathrm{M}$ and $1 \mathrm{M}$ of hydrogen peroxide concentrations relative to the lower concentrations due to the faster oxide layer growth on the surfaces.

The results of the electrochemical analyses were compared to the chemical mechanical polishing performance as a function of the $\mathrm{H}_{2} \mathrm{O}_{2}$ 


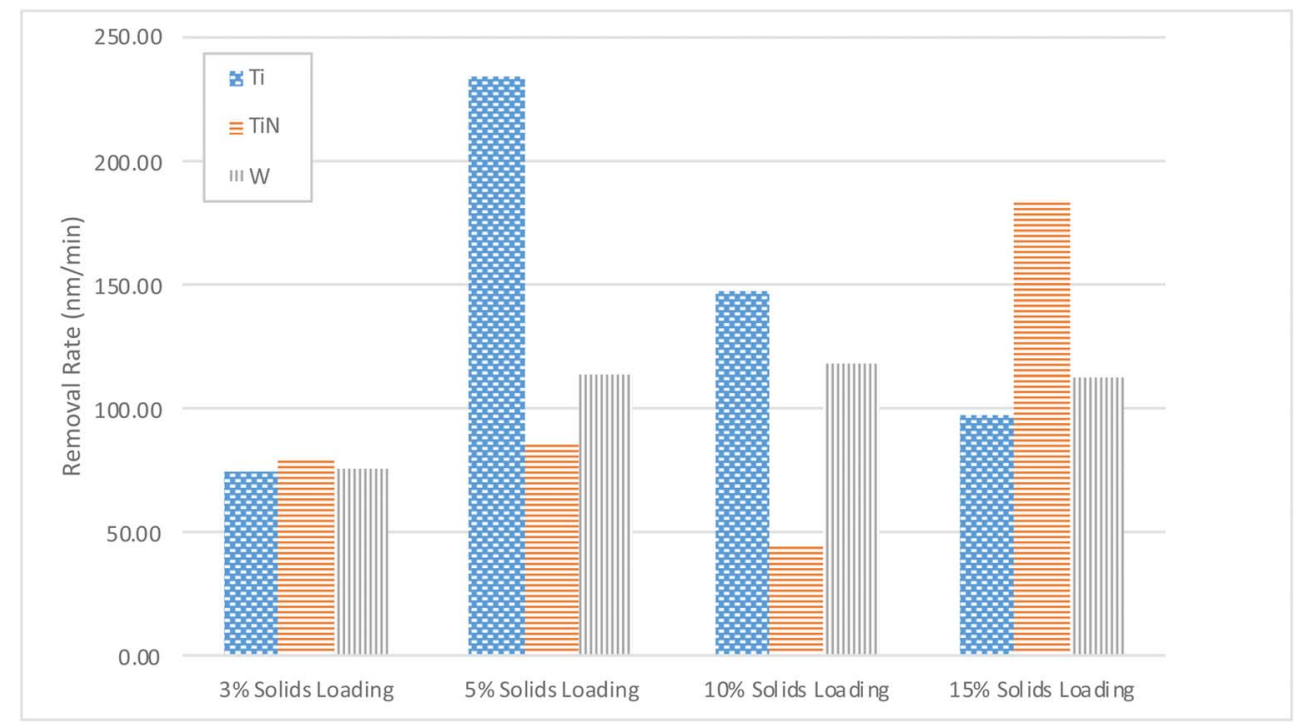

Figure 9. Material removal rates for Ti, TiN, and $\mathrm{W}$ wafers at $0.2 \mathrm{M} \mathrm{H}_{2} \mathrm{O}_{2}$ concentration with $3,5,10$ and $15 \mathrm{wt} \%$ slurry solids loading.

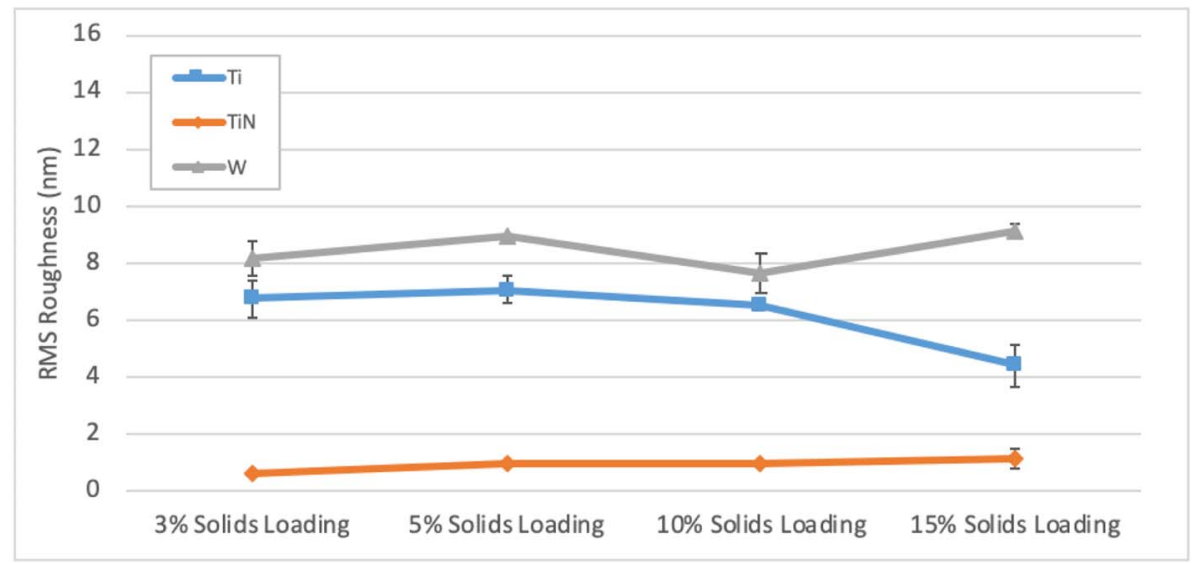

(a)
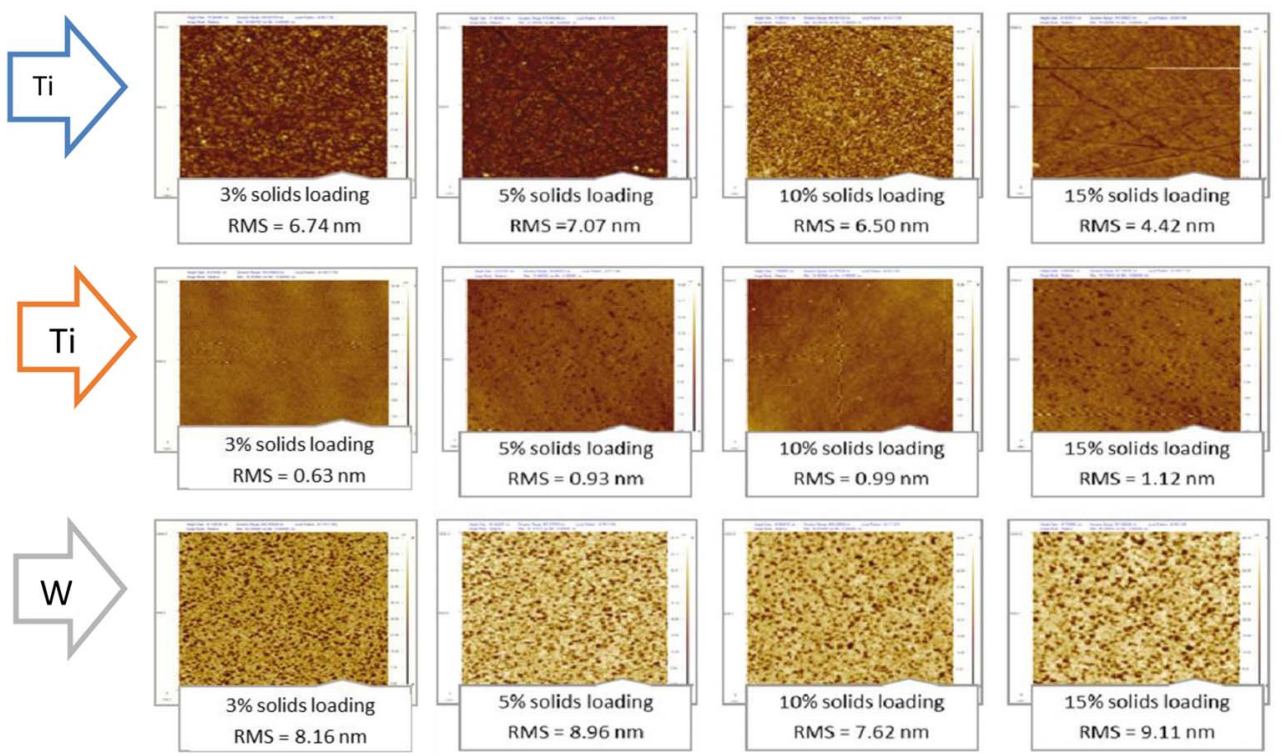

(b)

Figure 10. (a) RMS surface roughness data as a function of slurry solids loadings on W, Ti and TiN wafers at $0.2 \mathrm{M} \mathrm{H}_{2} \mathrm{O}_{2}$ concentration. (b) AFM surface micrographs of the W, Ti and TiN surface polished with 3, 5, 10 and $15 \mathrm{wt} \%$ slurry solids loading with $0.2 \mathrm{M} \mathrm{H}_{2} \mathrm{O}_{2}$ addition. 
concentration. It was observed that at $0.2 \mathrm{M}$ oxidizer addition, a 1/1/1 removal rate selectivity of $\mathrm{W} / \mathrm{Ti} / \mathrm{TiN}$ was achieved indicating a slurry formulation suitable to a single step metal barrier layer planarization. The surface roughness trends were similar to post electrochemical analyses with higher RMS roughness values obtained on Ti and $\mathrm{W}$ surfaces, while TiN surface remained smoother. The post CMP surface topography responses also corresponded to the trends in the surface wettability.

Based on the good removal rate selectivity achieved at $0.2 \mathrm{M}$ oxidizer concentration by controlling the slurry chemistry, the mechanical impact of the slurry solids concentration was also tested by running CMP experiments at 5, 10 and $15 \mathrm{wt} \%$ slurry solid loadings. It was observed that the change in the rate of mechanical abrasions affected the selectivity although the chemical activity remained unchanged. W film exhibited stable rates as a function of the slurry solids loading, while $\mathrm{Ti}$ and TiN showed varying MRR values. Overall, the results indicate that the MRR selectivity can be tuned by changing the chemical and mechanical compatibility of the CMP slurry based on detailed electrochemical evaluations. Hence it can be concluded that the advances in the CMP development for new barrier materials and integration schemes can benefit from the experimental approach outlined in this research.

\section{Acknowledgments}

The authors acknowledge Texas Instruments Inc. for providing the $\mathrm{W}, \mathrm{Ti}$ and TiN wafers and BASF SE, Germany for providing the baseline silica CMP slurry.

\section{ORCID}

G. Bahar Basim (iD https://orcid.org/0000-0002-2049-4410

\section{References}

1. Y. Obeng, J. V. Ramsdell, S. S. Deshpande, S. C. Kuiry, K. Chamma, K. Richardson, and S. Seal, "Impact of CMP Consumables on Copper Metallization Reliability," IEEE Transactions on Semiconductor Manufacturing, 18(4) (2005).

2. M. Krishnan, J. W. Nalaskowski, and L. M. Cook, "Chemical Mechanical Planarization: Slurry Chemistry, Materials, and Mechanisms," Chem. Rev., 110, 178 (2010).

3. H. B. Bhandari, J. Yang, H. Kim, Y. Lin, R. G. Gordon, Q. M. Wang, J.-S. M. Lehn, H. Li, and D. Shenai, "Chemical Vapor Deposition of Cobalt Nitride and its Application as an Adhesion-Enhancing Layer for Advanced Copper Interconnects," ECS Journal of Solid State Science and Technology, 1(5), N79 (2012).

4. M. He, X. Zhang, T. Nogami, X. Lin, J. Kelly, H. Kim, T. Spooner, D. Edelstein, and L. Zhao, "Mechanism of Co Liner as Enhancement Layer for Cu Interconnect Gap-Fill," J. Electrochem. Soc., 160(12), (2013).

5. J. Kelly, JH.-C. Chen, H. Huang, C. K. Hu, E. Liniger, R. Patlolla, B. Peethala, P. Adusumilli, H. Shobha, T. Nogami, T. Spooner, E. Huang, D. Edelstein, D. Canaperi, V. Kamineni, F. Mont, and S. Siddiqui, "Experimental study of nanoscale
Co damascene BEOL interconnect structures," Interconnect Technology Conference/Advanced Metallization Conference (IITC/AMC), 2016 IEEE International.

6. R. R. Patlolla, K. Motoyama, B. Peethala, T. Standaert, D. Canaperi, and N. Saulnier, "CMP Development for Ru Liner Structures beyond 14nm," ECS Journal of Solid State Science and Technology, 7(8), P397 (2018).

7. V. K. Dixit, K. Neishi, N. Akao, and J. Koike, "Structural and Electrical Properties of a Mn Oxide Diffusion Barrier Layer Formed by Chemical Vapor Deposition," IEEE Transactions on Device and Materials Reliability, 11(2), 295 (2011).

8. U. R. K. Lagudu, "Development of Formulations for a-SiC and Manganese CMP and Post-CMP Cleaning of Cobalt," Clarkson University, ProQuest Dissertations Publishing, (2014)

9. G. Yang, P. He, and X-P. Qu, "Inhibition effect of glycine on molybdenum corrosion during CMP in alkaline $\mathrm{H}_{2} \mathrm{O}_{2}$ based abrasive-free slurry," Applied Surface Science, 427, 148 (2018).

10. V. S. Chathapuram, T. Du, K. B. Sundaram, and V. Desai, Role of oxidizer in the chemical mechanical planarization of the Ti/TiN barrier layer, Microelectron. Eng. 65, 478 (2003).

11. K. Derbyshire, "Managing Parasitics for Transistor Performance," [online] Semiconductor Engineering. Available at:, https://semiengineering.com/ managing-parasitics-for-transistor-performance/(2017).

12. E. Kim, S. Shim, C. Jeong, and S. Lim, "A study of the interface phenomena of TiW/Si and TiN/Ti/Si'. Proceedings of 4th International Conference on Solid-State and IC Technology, (1995).

13. W. Xu, S. Liao, L. Jiang, J. Yang, and C. Yu, "Major influence of Ti/TiN and TTN metal barrier layer deposition on electro-migration resistivity,". 2012 IEEE 11th International Conference on Solid-State and Integrated Circuit Technology (2012).

14. M. Lapedus, "The Race to 10/7nm." [online] Semiconductor Engineering. https:// semiengineering.com/racing-to-107nm/ (2017).

15. P. Singer, "New Tungsten Barrier/Liner, Fill Processes Reduce Resistance and Increase Yield," [online] Semiconductor Manufacturing \& Design. Available at: http://semimd.com/blog/2016/06/03/new-tungstenbarrierliner-fill-processes-reduce-resistance-and-increase-yield/ (2016).

16. Y. Seo and W. Lee, "Effects of oxidant additives for exact selectivity control of Wand Ti-CMP process," Microelectronic Engineering, 77(2), 132 (2005).

17. A. Kargoz, V. Craciun, and G. B. Basim, Characterization of nano-scale protective oxide films: application on metal chemical mechanical planarization, ECS J. Solid State Sci. Technol., 4(2), 1 (2015).

18. Z. Ozdemir, A. Ozdemir, and G. B. Basim, "Application of chemical mechanical polishing process on titanium-based implants," Materials Science and Engineering: $C, \mathbf{6 8}, 383$ (2016).

19. N. C. Saha and H. G. Tompkins, "Titanium nitride oxidation chemistry: an X-ray photoelectron spectroscopy study," J. Appl. Phys., 72, 3072 (1992).

20. A. Karagoz, Y. Sengul, and G. B. Basim, "A Cahn Hilliard Modeling of Metal Oxide Thin Films for Advanced CMP Applications," ECS Transactions, 61(17), 15 (2014).

21. Y-J. Seo and S-W. Park, "A Study on the Electrochemical and the Chemical Mechanical Polishing Behaviours of W and Ti Film," Journal of the Korean Physical Society, 50(3), 643 (2007).

22. X. Liu, P. Chu, and C. Ding, "Surface modification of titanium, titanium alloys, and related materials for biomedical applications," Materials Science and Engineering: R: Reports, 47(3-4), 49 (2004).

23. C. Y. Chao, L. F. Lin, and D. D. Macdonald, "A Point Defect Model for Anodic Passive Films," J. Electrochem. Soc., 128, 1187 (1981).

24. S. Bargir, S. Dunn, B. Jefferson, J. Macadam, and S. Parsons, "The use of contact angle measurements to estimate the adhesion propensity of calcium carbonate to solid substrates in water," Appl. Surf. Sci., 255, 4873 (2009).

25. G. B. Basim and A. Kargoz, "Metal Oxide Thin Film Characterization for New Generation Chemical Mechanical Planarization Development," ECS Transactions, 72(3), 67 (2016).

26. S. Ozbek, W. Akbar, and G. B. Basim, "Optimized Process and Tool Design for GaN Chemical Mechanical Planarization," ECS Journal of Solid State Science and Technology, 6(11), S3084 (2017). 